\title{
You're damned if you do and damned if you don't - The tension-filled relationships between Japanese beginning and senior teachers
}

Erkki T. Lassila ${ }^{a^{*}}$, Minna Uitto ${ }^{\mathrm{b}}$ and Eila Estola ${ }^{\mathrm{b}}$

${ }^{a}$ Faculty of Education, University of Oulu, Finland and Institute for the Advancement of Higher Education, Hokkaido University, Japan; ${ }^{b}$ Faculty of Education, University of Oulu, Finland

Erkki T. Lassila, Faculty of Education, P.O. Box 2000, 90014 University of Oulu, Finland (current) / Institute for the Advancement of Higher Education, Kita 17, Nishi8, Kita-Ku, Sapporo, Hokkaido University, 060-0817, Japan, tel.+35850-4648358, email: erkki.t.lassila@oulu.fi,orcid.org/00000002-6676-966X; Minna Uitto, Faculty of Education, P.O. Box 2000, 90014 University of Oulu, Finland, tel. +358294483729, email: minna.uitto@oulu.fi , http://orcid.org/0000-0001-9180-4415; Eila Estola, Faculty of Education, P.O. Box 2000, 90014 University of Oulu, tel. +358-503501885, email: eila.estola@oulu.fi, http://orcid.org/0000-0002-3451-5470

This work was supported by the Academy of Finland (Grant no. 265974: Disentangling the emotional dimension in beginning teachers' work); by a Japanese government scholarship (Monbukagakusho: MEXT); and by the Finnish Cultural Foundation (Grant no. 00130492 and Grant no. 00160538).

Corresponding author. Email: erkki.t.lassila@oulu.fi 


\begin{abstract}
This article contributes to the theoretical discussion of beginning teachers' work as being both relational and emotional. Specifically, we have examined the tensions that frequently characterise the relationships between beginning and senior teachers. Our research material consisted of narrative interviews with seven beginning teachers and seven senior teachers working at the same junior high school in Japan. Through thematic analysis, we have identified three categories of tensions: 1) tension between dependence and independence, 2) tension between obedience and assertiveness and 3) tension between loyalty to one's students and loyalty to one's colleagues. These tensions are meaningful for both beginning and senior teachers, but they view them in different ways and connect them to different expectations regarding appropriate actions and attitudes. These tensions are also related to wider cultural expectations and general principles that are often concretely realised through different practices within the micropolitical environment of a school.
\end{abstract}

Keywords: Beginning teachers; educational relationships; emotions; Japan; narrative approach; senior teachers; tensions

\title{
Introduction
}

When researchers have investigated the relationships involved in teachers' work, the focus has typically been on either relationships in general or on teacher-student relationships (e.g., Aultman, Williams-Johnson, and Schutz 2009; Hargreaves 2000; Newberry 2010), especially in regards to beginning teachers, for whom the relationships with their students are a key challenge of their early careers (e.g., Veenman 1984). Outside the few notable exceptions, including Hargreaves' (2001) studies of the varied emotions tied to collegial relationships and Kelchtermans' (2005) work on the micropolitical lives of teachers, the relationships with colleagues have rarely been in the research spotlight. However, the importance of colleagues for beginning teachers, especially on learning to 
cope with the challenging nature of the work and developing their skills, are increasingly being acknowledged in educational research literature (e.g., Lassila and Uitto 2016; Devos, Dupriez, and Paquay 2012; Le Maistre and Paré 2010). The relationships with colleagues are especially important for beginning teachers, who are struggling to find their place in the teacher community (Kelchtermans and Ballet 2002).

The relationships with colleagues can be extremely rewarding emotionally, but they can also potentially create the most negative emotions related to teachers' work, especially in the early career phase (Devos et al. 2012; Hargreaves 2001). Currently, there is still little understanding of how beginning teachers deal with the relational dimension of their work within different school environments (Peters and Pearce 2012) and the different tensions tied to these relationships. The present study aims to fill this gap in the literature, where tensions are acknowledged as inherent to teaching (Andô 2005; Berry 2008; Clandinin et al. 2009), by examining tensions in relationships between beginning teachers and their senior colleagues. By analysing stories of beginning and senior teachers who work in the same school, we seek to answer the question, What kinds of tensions characterise the relationships between beginning and senior teachers? Answering this question will produce knowledge about the the relational nature of teachers' work and its tensions. In the last section we discuss the implications our findings have for teachers' work and teacher education.

According to Kelchtermans and Ballet (2002), tensions in relationships may be connected to beginning teachers having to negotiate their place within the school's organisational reality. In this regard, they must pursue their own professional interests while being mindful of the interests of the broader teacher community; these two types of interests are often in conflict (Kuzmic 1994; Miyajima 2008). In other words, norms prioritised in schools may conflict with ideas held by beginning teachers themselves (Andô 2005), or contextual issues may limit the extent to which beginning teachers can work according to their ideals (Lassila and Uitto 2016). By acknowledging 
these tensions inherent to teachers' relationships (Clandinin et al. 2009), we take a close look at the relationships between beginning teachers and their senior colleagues, who are known to exert a strong influence on how beginning teachers conduct their work. This is especially true in the Japanese context where seniority plays a major role in social and organizational hierarchy (e.g. Sugimoto 2003), which inevitably influences collegial relationships (Miyajima 2008; Shimahara 2002). This is why we chose a Japanese junior high school as the setting for our study.

While it has been argued that tensions can motivate professional growth, they are also a source of stress and have the potential of becoming an emotional burden (Flores 2004; Pillen, Beijaard, and den Brok 2013). Whether these accompanying emotions are interpreted as negative or positive is influenced by the resources available to the teacher for dealing with them. It is important to address the relational tensions that beginning teachers face because they can also become a reason for leaving the profession early on, especially if not enough support is given to cope with them and the accompanying emotions (Toompalu, Äli and Kullasepp 2016; Wakimoto and Chôshi 2015).

\section{Theoretical background}

In line with earlier research, we use the term beginning teacher to refer to someone who has worked for 0 to 5 years (Caspersen and Raaen 2014). Previous research on beginning teachers has often focused on obstacles to entering the field, which include difficult relationships with students, the surprisingly onerous workload and the problem of teacher attrition (e.g., Ballet and Kelchtermans 2009; Peters and Pearce 2012). The emotional challenges of the first few years of teaching have also been explored (Caspersen and Raaen 2014). In addition, prior research has discussed the difficulties of entering the school's micropolitical environments (conceptualised as places where teachers use power to advance various personal and professional interests) with often complicated collegial relationships (e.g., Hargreaves 2001; Kelchtermans and Ballet 2002). The present study aligns most closely with this latter strand of research. 
We understand teachers' work as a relational practice, where emotionally strong relationships with students and colleagues form a meaningful core for the profession (Hargreaves 1998). The construction of these relationships is influenced by the context - that is, by the organisational structure of the school, educational policies and the wider surrounding culture. In Japan, teachers' professional growth is closely tied to the professional community of the school via official in-service trainings (kenshu) and a more tacit culture of learning how to teach through senior teachers' examples and advice (Howe 2005; Shimahara 2002). Kelchtermans and Ballet (2002) noted that while having the opportunity to work with children may be the reason for choosing to become a teacher, the professional collegial environment and its relationships arguably constitute one of the most important working conditions. For example, senior teachers often embody the culture of their school, socialising newcomers to the profession (Zeichner and Gore 1990). In addition, expectations expressed by the teaching community and through the school's micropolitical environment and practices often engender tensions by clashing with beginning teachers' expectations and ideals about their own work as a teacher. These expectations are also tied to ideals and images regarding teachers and their work expressed in the wider culture - in this study, the strongest expectations were related to the way the teachers' work is defined as taking place within the sphere of senpai-kôhai (senior-junior) relationships.

In Japan, teachers' work is characterised by interdependence, camaraderie that often involves a strong emotional connection, sharing of experience and information and an ethos of equality based on which all teachers, regardless of age or work experience, are expected to be treated as full professionals and intruding on others work is avoided (Okano and Tsuchiya 1999; Shimahara 2002). Vertical relationships take the form of senpai-kôhai positions, which are central to the power dynamics of the teachers' work (Miyajima 2008). Senior teachers are expected to teach, discipline and nurture their kôhai, who are expected to respond with gratitude, respect and a willingness to obey (Rohlen 1991). Teachers' professional learning is understood to take place 
through immersion in a shared repertoire of practices to compensate for the limited teaching practicum during their teacher education studies (Howe 2005; Shimahara 2002). As virtual apprentices, beginning teachers are expected to actively look to their seniors for guidance and good pedagogical examples, to some extent viewing them as active mentors (Shimahara 2002). However, the beginning teachers are also treated as fully fledged professionals and are assigned tasks and responsibilities accordingly (e.g., Harfitt 2015). These strong cultural positions of beginning and senior teachers constitute a framework for understanding the teachers' stories in this study.

Although the expectations placed on beginning teachers vary depending on their specific working environment, they all have to decide how to respond to these expectations. Beginning teachers hold various professional interests, which inform and influence the different choices they make in their everyday work. In trying to establish, maintain or restore ideal working conditions that align with their various professional interests, these teachers may act based on their own values and obligations, and these do not necessarily align with those of other teachers (Kelchtermans and Ballet 2002). These differing interests can lead to conflict and negotiations, which have been identified as a significant source of tension (Pillen et al. 2013). While the mechanisms underlying these tensions may differ, we agree with Clandinin et al. (2009) that these tensions are relational in nature and an inevitable and unresolvable aspect of teaching. Dealing and coping with these tensions can arouse a range of intense emotions (Meijer 2011), and because relationships with colleagues carry potential for conflict - both professionally challenging and emotionally taxing beginning teachers resort to various strategies to avoid them. For example, they may abandon their own beliefs (Lassila 2017; Uitto et al. 2015), establish norms of politeness or non-interference or resort to lukewarm interactions (Ávila de Lima 2001).

Emotions are an inseparable aspect of human interaction, and as we understand teachers' work as a relational practice, we need to also address its emotional dimension (Hargreaves 1998; Nias 1996). Nias (1996) has elaborated on the importance of emotions in teaching and for teachers. 
She argues that teachers are emotionally invested and feel intensely about their work. Teachers' personal and professional identities are often so inseparable that their lives in the classrooms and schools become intertwined with their self-esteem, sense of fulfilment and vulnerability. We understand emotions not just as the private and psychological experiences of an individual, but as social in nature, influenced by the norms of the surrounding culture and resulting from teachers' interaction with their professional environments (Kelchtermans 2005; Zembylas 2004).

In this study, we have examined the tensions and accompanying emotions through the concept of school as a micropolitical environment where the focus is on the relational dimension of teachers' work, their process of negotiation and their use of power to achieve their goals and professional interests (Kelchtermans and Ballet 2002; Kelchtermans 2005). The micropolitical environment of the school is conditioned by the wider macropolitical context and the surrounding culture. This micropolitical environment is interpreted differently by its members according to their backgrounds, experiences and positions. (Smeed et al. 2009.) The micropolitical perspective is particularly significant because of how the collegial relationships in Japanese schools are influenced by vertical power relationships i.e. the positions of senpai and kôhai (senior-junior).

\section{Conducting the research}

\section{The narrative approach}

In our research we employ narrative approach, according to which we understand that teachers make sense of their own lives and the world they live in by narrating their experiences (Clandinin and Connelly 2000; Elbaz-Luwisch 2005). Teachers' stories are both personal and deeply embedded in the broader social, cultural and political dimensions of their environments, and due to this connection between their experiences and their context, it is possible to examine wider issues through their stories (Spector-Mersel 2010; Lieblich, Tuval-Mashiach, and Zilber 1998). Additionally, utilising the three spheres of contexts conceptualised by Zilber, Tuval-Mashiach and 
Lieblich (2008) has allowed us to closely examine the specific conditions influencing what stories the teachers have told and why these stories matter.

The first relevant context is the immediate intersubjective relationship where the story is produced. In our research, the participating teachers were likely doing status work to tell themselves as certain kinds of beginning or senior teachers to the foreign researcher, perhaps trying to portray themselves in a positive light (Gubrium and Holstein 2008). Perhaps they even saw themselves representing all Japanese teachers. In addition to the fact that Erkki came from Finland and had a background in teaching, his age and gender, among other factors such as conducting the research in Japanese $e^{\mathrm{i}}$, potentially influenced the researcher-participant relationship and consequently the nature of the participants' narrations (Moje 2000).

The second relevant context is the collective social field in which life and stories of experiences evolve (Zilber et al. 2008). The particular junior high school where all the interviewed teachers worked was the most meaningful environment in regards to how the teachers narrated their work. The positions that the teachers occupied in the school and the amount of work experience could be seen influencing their narrations. Similarly to Britzman (2003), we noted how the stories of the beginning teachers, who were just learning the language of teaching, differed from the senior teachers, who had already made the language their own. The teachers were also aware that Erkki was interviewing and talking with other teachers as well, and this likely influenced what and how they felt they could tell about their collegial relationships.

The third context is the metanarratives and systems of cultural meaning that frame every story told (Zilber et al. 2008). In our research, the stories were told by Japanese teachers. Therefore, the often implicit rules that influence communication between Japanese people, as well as the values guiding pedagogical decisions and teacher ideals, can be seen as meaningful for the narration. 


\section{The research context and production of the research material}

K-school (pseudonym) provided the main setting for this research. It is a typical Japanese public junior high school in a major urban centre with 300 to 400 students of average academic level and over 30 teachers. At the time of the field research, there were 7 beginning teachers ( 0 to 5 years of experience) and 2 midcareer teachers ( 8 to 20 years of experience); the rest were senior teachers (over 20 years of experience). Japanese junior high school teachers are subject specialists and typically also assume responsibilities related to homeroom guidance and after-school club activities. The school had some disaffected and restless students, but the teachers frequently commented in the interviews and private discussions how the school was an easier working environment than other schools in the area. Class sizes ranged from 30 to 40 students, and lessons were often teachercentred lectures.

Access to Japanese schools is not easily obtained, but through a personal contact and permission from the principal, Erkki was able to spend 6 weeks at K-school between February and April in 2014. During this period, Erkki went to the school daily and participated in the everyday lives of the teachers and students. He made field notes and also conducted initial interviews with the beginning teachers. He subsequently visited the school at frequent intervals, conducting second interviews with the beginning teachers (including first interviews with two newly arrived teachers) and interviewing the senior teachers. Erkki conducted the final interviews and completed his field notes in May 2015, marking the end of his active involvement in the school. Between the first and last visit, he had his own desk in the staff room, an important signifier of being accepted as a member of the community (Ahn 2014). He was also invited to spend time with the teachers at informal gatherings outside official work hours.

The main research material gathered from K-school consisted of interviews with seven beginning teachers and seven senior teachers. Conducted in a library or other quiet room, the interviews ranged in duration from 30 to 75 minutes; all were conducted in Japanese by Erkki, who 
is proficient in the language. Each interview began with an invitation to tell a story about becoming a teacher; from there, the interview progressed in a more discussion-like manner. Stories about relationships and emotions were solicited when they did not emerge naturally. Beginning teachers were asked to recount their experiences as junior members of the teacher community, and senior teachers were asked about their relationships with the beginning teachers.

The participating teachers covered most of the subjects taught in junior high schools. Female and male teachers were more or less equally represented among both the beginning and senior teachers. Most of the beginning teachers were employed on temporary contracts as they had not yet passed the employment examination; ${ }^{\text {ii }}$ however, all had homeroom responsibilities. Those senior teachers whom Erkki observed as interacting the most with the beginning teachers were interviewed. These included three teachers who were in charge of all the teachers for a particular grade level - a responsibility that included taking care of the group's beginning teachers.

As stated previously, Erkki kept field notes writing down descriptions and reflections on daily life in the staff room and at the school. These extensive field notes in Finnish, were used to contextualise the findings.

\section{Analysis}

Earlier, we had identified that collegial relationships and a vertical hierarchy were sources of tension in beginning teachers' relationships with their students (Lassila and Uitto 2016). With this in mind, Erkki read all the transcripts (in Japanese) of the beginning and senior teachers' interviews and went over his field notes to identify any signs of tension associated with the relational dimension of the teachers' work. One common thread that he noticed was that the beginning and senior teachers talked differently about the same situations.

Based on this finding, Erkki compiled and translated into English all accounts from the interviews that referred to collegial relationships and tensions. We then performed a thematic 
analysis of these accounts and identified three different tensions in the relationships between the beginning and senior teachers: 1) tension between dependence and independence, 2) tension between obedience and assertiveness and 3) tension between loyalty to one's students and loyalty to one's colleagues.

Finally, we reread selected accounts from the research material, focusing on the emotions related to these different types of tensions in the teachers' collegial relationships. Emotions were sometimes explicitly mentioned in the accounts. In addition, we used the following means to identify implicitly present emotions. If we understand emotions as a means of determining the importance of things around us (Nussbaum 2001) and that in interviews participants recount events meaningful to them, i.e., important in the emotional sense (Kelchtermans 1994), we can see that emotions are always present when anyone is narrating. Furthermore, repetition in an interview implies that the content of the narration has emotional salience for the teller, and we can assume that emotion is present when a narration takes place in a context where emotional experiences are asked for. Erkki directly asked the teachers to talk about positive and negative relational experiences. Finally, emotionally meaningful moments are usually those recalled best when talking about past events; this was also the case with our teacher interviews (e.g., Southgate 2003).

Rather than focusing on the teachers' individual stories, we performed a thematic analysis to protect the teachers' anonymity and to ensure that collegial relationships would not suffer because of something they said. Therefore, the participants are referred to as Beginning teacher 1, Senior teacher 1, etc., and 'she' is used for all teachers. The teachers whose accounts are included in this article were given the option of commenting on the manuscript before submission for publication. This kind of check is commonly used to increase the veracity of interpretations and to respect the ethical commitment to the researcher-participant relationship (Josselson 2007). 


\section{Findings}

\section{Tension between dependence and independence}

The first tension we identified in the relationships between the beginning and senior teachers relates to how the beginning teachers were expected to be confident and independent while at the same time conforming to and depending on the senior teachers (see Britzman 2003). In the accounts of the senior teachers, this tension seemed to relate to the expectation that they should guide the beginning teachers firmly while also allowing them to learn on their own. One senior teacher, for example, talked about this expectation when comparing two beginning teachers, commenting on the issue of independent performance:

The most trustworthy is [a particular beginning teacher] who always thinks for herself rather than relies on others to tell her what to do. Although she has only 4 to 5 years of experience, it feels like she has been working for much longer than that. [Another beginning teacher] on the other hand has a good personality, but as expected, after her first year, she still doesn't know instinctively what she should be doing as a teacher, especially in the company of other teachers. (Senior teacher 1)

This particular senior teacher described that the beginning teachers should ideally be able to anticipate other teachers' needs and to plan and execute their work without being directly instructed. While those beginning teachers who could do so were seen as independent and strong, others were implicitly criticised. In this account, the senior teacher even identified particular beginning teachers by name when characterising these teachers' abilities to be independent. However, as demonstrated in other stories, especially those of the beginning teachers, the issue of dependence and independence is not that straightforward.

I don't think I could do the job relying only on my own skills; I always ask for advice from my seniors. Based on their comments and encouragement, I can work with full confidence. I could not be this positive and energetic without them. I have to be alert all the time when 
dealing with the people around me because if my relationship with them deteriorates, it will be a personal catastrophe. (Beginning teacher $1,1^{\text {st }}$ interview)

This beginning teacher credits the senior teachers with empowering her to act independently, confirming the importance of well-functioning collegial relationships for beginning teachers. The emotional tone of this teacher's account is grateful, but the mention of "a personal catastrophe" also hints at the fear of losing the support of her senior teachers if the collegial bonds are broken (Hargreaves 2001). Her account illustrates that she seems to depend on senior teachers, highlighting that dependence is actually a way of positioning oneself in relation to others - that is, assuming the safe position of an obedient and dependent kôhai (junior). This dependence extends to concerns about one's growth as a teacher, as can be seen in an account of another beginning teacher:

This school's relative absence of arguments, conflict and strict seniors is actually a bit frightening because those things help beginning teachers to learn. Here, you have to notice things yourself and take responsibility for your own growth. (Beginning teacher 2, $1^{\text {st }}$ interview)

According to this teacher, at her previous school, she had learned to rely on the direct comments and guidance of her seniors, but when this did not happen at K-school, she felt neglected. This can be a daunting experience for a beginning teacher (Uitto et al. 2015) and illustrates the clear expectations of beginning teachers regarding their relationships with senior colleagues. Here again, the leading emotional tone is fear and uncertainty. This account also further illustrates how beginning teachers may want to be given direct advice. Partly behind this expectation can be the need to be noticed and acknowledged, but the expectation is also related to the culturally pervasive model of understanding learning as taking place through examples given by those considered more knowledgeable (e.g., Kondo 1990). 
The culture observed at K-school of not commenting on a beginning teacher's work can be seen connected to the aforementioned ethos of equality, which may limit the teachers' involvement with each other's work (Okano and Tsuchiya 1999). However, if senior teachers refrain from guiding the beginning teachers, this may be seen as contrary to the interests of both the organisation and the beginning teachers themselves, who may feel that they cannot cope without this support (Kelchtermans and Ballet 2002). Beginning teachers often struggle with finding their own standing within the network of a school and figuring out how to reach out for help, but the following account illustrates that when properly functional, the senpai-kôhai system can be helpful.

I am quite reserved with new people and not really good at interacting with those who are older than me, and in the beginning, I did struggle quite a bit with my work relationships, but the senior teachers invited me frequently to dine with them and in the staff room often asked me if I was having any problems and gave suggestions on how to do things, so instead of me having to make an effort, the people around me reached out to me. (Beginning teacher $3,1^{\text {st }}$ interview)

In this account the beginning teacher describes how the senior teachers did indeed offer their help, even without being asked. There are two possible interpretations for the position of the beginning teacher in this kind of situation: On one hand, the teacher brought up that she was helped in many ways by the senior teachers looking after her. However, on the other hand, this eagerness of the senior teachers to help seemed to have also negative meaning: The teacher did not have to 'make an effort' in her relationships with the senior teachers, thus preventing her from improving her communication skills, important also for other social contexts.

The next account shows how one senior teacher talked about the expectations for them to function as caring senpai:

If possible, I would stay until 7 or 8 p.m. and perhaps invite the young teachers to eat and to have a chat about the difficulties at work. It is a shame it does not happen that much 
anymore, but during work hours I try to communicate a lot and offer advice to young teachers who seem to be having trouble. (Senior teacher 2)

While it came up in the interviews that the senior teachers expected the beginning teachers to manage many things on their own, based on this account they also helped and offered guidance to the beginning teachers and seemed to understand the expectations and responsibilities placed upon them. In the accounts of the senior teachers, tension came from trying to find a good balance between actively guiding the beginning teachers and leaving them to figure things out on their own. In the accounts of the beginning teachers, on the other hand, finding a balance between asking for help from senior teachers and struggling on one's own was a major source of tension. Therefore, it seems that one important skill for the beginning teachers was knowing how to ask for help in a way that allowed them to appear independent, even if in reality they were still depending on the senior teachers.

\section{Tension between obedience and assertiveness}

The second tension we identified in the relationships between the beginning and senior teachers relates to how the senior teachers expected the beginning teachers to contribute to running and developing the school and to be more assertive. However, at the same time, strong cultural and organisational expectations required that the beginning teachers assume the position of an obedient kôhai (junior). This tension relates both to the professional growth of the individual teacher and to the school's teacher community as a whole. Speaking as caring senpai, the senior teachers, as the next account illustrates, often voiced the expectation that beginning teachers should express new ideas, defend their opinions more strongly and be more assertive and try new things:

I want them to fail a lot more - to take on challenges, which I know from experience will deepen their views on teaching. I often say to the young teachers, 'Try a lot harder', but they just seem to avoid confrontation and do everything cautiously. (Senior teacher 3) 
This account illustrates how the senior teacher expected the beginning teachers to be innovative and willing to try new ideas even if they could potentially fail. However, this account does not bring up the cultural and organisational expectation that emphasises the obedience of beginning teachers to their seniors. The senior teachers often seemed to not take into account the fact that, unlike themselves, the beginning teachers are relatively voiceless because of their junior position (see Miyajima 2008). The beginning teachers, on the other hand, often referred to their constrained position and expectations related to silence and not standing out. As one beginning teacher described:

I'm a young teacher. I just graduated from university and have worked for a couple of years. Unlike the older teachers, I feel like I'm still somewhere between a child and a real adult, so I cannot express my opinions strongly. I hesitate to comment on how to educate the students. After gaining some more experience, I can perhaps contribute to the change of the atmosphere more directly. (Beginning teacher $2,1^{\text {st }}$ interview)

Here, the beginning teacher attributes her voicelessness directly to her junior position by saying that she is not yet a real adult, but she anticipates that her ability to speak will change with seniority and experience. By saying 'I hesitate', this teacher seems to express uncertainty and even a hint of fear of losing credibility connected to taking an active position within the community.

Many of these beginning teachers were also on a part-time contract, further limiting their possibilities for action and their ability to be heard. There were almost no midcareer teachers ${ }^{\mathrm{iii}}$ at the school who might better understand and respond to the beginners' needs, which may have further deepened the voiceless position of the beginning teachers. This significant gap in age brought a parental quality to the beginning teacher-senior teacher relationship, making communication from the beginning teacher's side quite cautious. This distance narrowed during social events (often nomikai $^{i v}$ ), where teachers could speak more freely with each other (Field notes, March and May 2014). 
In the first years of teaching, teachers tend to be quite conservative; they do not vocalise their opinions, they avoid any 'rebellious' actions and they abandon their own ideas in favour of others to avoid any situation that might lead to conflict (Kuzmic 1994; Uitto et al. 2015). One beginning teacher described how she heeded her senior's suggestion to deny one student access to her afternoon club so that the student would take her schoolwork more seriously, even though the teacher personally considered this too harsh a punishment:

Even though I thought that forbidding the student from joining in the club activities that meant quite a lot to him was a bit too much, we did as she [the senior teacher] suggested and everything went well. I learned a lot from the experience. (Beginning teacher $4,2^{\text {nd }}$ interview)

Even though the beginning teacher did not get to enact her pedagogical ideal, the emotional tone is neutral and suggests that the teacher did not see it as a big of a deal. The account illustrates how beginning teachers are willing to sacrifice their self-interest in favour of organisational or social-professional interests, most important of which is the support from their seniors (Kelchtermans and Ballet 2002; Kelchtermans 2005).

Next, we take a look at an episode where a beginning teacher took an assertive stance. In the second interview, this teacher talked about how she felt about different rules of the school and her relationships with her senior colleagues:

I hate saying things to children that have not even crossed my mind as being important. There is a great age gap between me and the older teachers, and because of it, what is common sense to them is not common sense for me. I do not like lying or telling children that they cannot do something when I do not agree with the rule myself. Because of this, many of the things I say do not get through to the children well. (Beginning teacher 2, $2^{\text {nd }}$ interview) 
In her first interview, this teacher explained where this attitude came from, recounting what came to be referred to as 'the candy incident'. She challenged the norms of the school during this particular event, where the consensus was that students should not be allowed to bring sweets into the school. This beginning teacher disagreed with this unwritten rule and tried to reason with the senior teachers, but she failed to get through to them.

I told my students in the homeroom time about the sweets thing, but because in my heart I did not approve to the rule, I used such an ambiguous phrasing that they probably thought that bringing sweets would be okay as long as nobody saw it. (Beginning teacher $2,1^{\text {st }}$ interview)

The students ended up bringing sweets to school, and things escalated quickly. The following week's club activities were cancelled, harsh lectures were read to the students and the beginning teacher also had lengthy discussions with the principal and vice principal about her work and attitude towards it. (Field notes, February 2014)

This account, where the beginning teacher ignores the expectation to be obedient and takes an assertive action, is an example of how the tension appears in the everyday relationships between the beginning and senior teachers. This emotionally laden account also illustrates the beginning teacher's disapproval towards certain rules and practices promoted by the senior teachers. Looking at how the events unfolded, it seems understandable that the beginning teachers might refrain from asserting their views and interests as there is possibility of similar repercussions. Another side of this tension is illustrated in the following interview of a senior teacher, who described her difficulty with deciding how best to 'train' her junior teachers. Although, as senpai, the senior teachers are expected to critique and challenge their kôhai, they sometimes may refrain from doing so.

The beginning teachers don't know how to take criticism. Young people avoiding situations where they might be criticised by their seniors is a trend in today's Japan. They have been 
raised as too precious, and they lack the strength to persevere when encountering difficulties. (Senior teacher 3)

Here, the senior teacher describes the beginning teachers as being unable to accept the reasonable criticism that their senior teachers were expected to provide. Some of the senior teachers even mentioned that they refrained from being strict towards the beginning teachers unless absolutely necessary, as the next account demonstrates:

When I was a young teacher, older teachers said pretty harsh things and got mad at me quite often, but young teachers nowadays aren't used to being yelled at. Because of that I try not to say things too harshly so they don't lose their confidence completely. It's quite difficult when the things that you've learned in the past can't be applied in the current situation. (Senior teacher 4)

This account further illustrates how, for the senior teachers, the tension between obedience and assertiveness is linked to knowing that the beginning teachers need to be disciplined to promote their professional growth and for proper functioning of the school while also being concerned about potentially harming the beginning teachers.

\section{Tension between loyalty to one's students and loyalty to one's colleagues}

The third tension we identified in the relationships between the beginning and senior teachers is related to the beginning teachers' loyalty towards their students and the energy devoted to these relationships. However, a focus on student relationships may conflict with the expectations placed upon the beginning teachers as members of the teacher community. This tension arises from conflicting loyalties to teaching and guidance and to the organisation, putting the beginning teachers under considerable stress (Ballet and Kelchtermans 2009; Wakimoto and Chôshi 2015). Given these competing responsibilities, the beginning teachers have to make tough decisions about where to invest their time and energy. 
The expectation that beginning teachers will work to create a strong emotional bond with their students has long represented the ideal for teacher-student relationships (e.g., Shimahara 2002), and virtually all of the beginning teachers articulated this as a major reason for becoming a teacher:

I want to leave a mark on this world through the children I work with. (Beginning teacher 3, $1^{\text {st }}$ interview)

I wake up every morning thinking that today, too, I can spend time with the students I really like. I really love them and always think: 'today I will put in my best effort with them'.

(Beginning teacher $1,1^{\text {st }}$ interview)

Additionally, many of the teachers indicated that 'working for the students' was a guiding principle behind many practices and decisions made at K-school (Field notes, March 2014). In their stories, the beginning teachers talked most about how they created relationships with students and how they managed their teaching tasks. It was clearly the most important part of the work for them. Therefore, it is reasonable to assume that beginning teachers wished that the senior teachers would emphasise the teacher-student relationships when assessing their performance as teachers. Indeed, their skills with students were often assigned great importance, but the senior teachers actually talked more about other aspects of the beginning teachers' work in the interviews — such as acting as a member of the teacher community. One senior teacher stated:

[One particular beginning teacher] has a good personality, but as expected, after her first year, she still doesn't know instinctively what she should be doing as a teacher, especially in the company of other teachers. (Senior teacher 1)

This account illustrates how not knowing how to act as a member of the teacher community was considered more important by the senior teachers than the beginning teachers' actual teaching capabilities. This senior teacher went on to describe another beginning teacher: 
She [a particular beginning teacher] should have had a flu shot and kept herself healthy in order to finish her important task in time... she is really [amai] as an adult member of the society and lacks the skills to read things ahead of time, to act accordingly and to prioritise her tasks properly. If she doesn't get opportunities to develop those skills, it's going to be difficult for her. (Senior teacher 1)

In this account, being amai (naïve, inexperienced, soft) seems to refer to this beginning teacher's lack of sense of responsibility, as the senior teacher states that the teacher did not take proper care of her health. The expectation that she should work hard for the teacher community is very clear, echoing the cultural ideal of self-sacrifice which has been a part of teaching culture in Japan (Andô 2005). Because schools are managed cooperatively by teachers with interdependent and quite diffuse roles, teachers can and must cover for each other when someone is absent (Shimahara 2002). Therefore, having a heightened sense of responsibility as a member of the community is considered paramount in Japanese institutions operating with limited staff (Raz 2002).

Many of the accounts of the beginning teachers emphasised the importance of building pedagogical relationships with students from both a cultural-ideological perspective and as a matter of self-interest (Kelchtermans and Ballet 2002); for many beginning teachers, this was a major element of their professional identity and their main reason for entering the teaching field. Our findings highlight how those interests collide with the organisational interests of senior teachers, who see the beginners as team members above all, sharing responsibility for managing the school.

\section{Discussion}

In exploring the tensions that characterise the relationships between beginning and senior teachers, we have identified three kinds of tensions. Firstly, the beginning teachers are expected to both act independently and to rely on the guidance of their seniors. Secondly, the beginning teachers are expected to voice their own opinions and to be assertive, but they are paradoxically also 
reprimanded if they break away from the position of an obedient kôhai (junior). Thirdly, the tensions are related to where the loyalty of the beginning teacher lies: towards the students, who should be at the centre of their work, or towards colleagues, who demand attention and commitment to running the school? In earlier research, beginning teachers were found to experience conflict between their loyalties towards their students and colleagues, but in those cases, it was related to protecting students (e.g., Shapira-Lischinsky 2011).

Contrary to earlier research (e.g., Pillen et al. 2013), our research focused on tensions in the relationships between beginning and senior teachers from the perspectives of both the beginning and senior teachers. The research illustrates how the relational tensions are tied to contradictory expectations on beginning and senior teachers, who see and approach the same situations from their respective positions. Based on this, we suggest that tensions are present in teachers' work, but change in different stages of the teachers' careers. It is reasonable to assume that the amount of work experience a teacher has will impact her ability to deal with these tensions, but further research is needed to find out whether and how this changes over time.

In this article, we have highlighted how the relational tensions among teachers are strongly connected to differing expectations (about appropriate actions and attitudes). These tensions are micropolitical in nature in the sense that they are not openly discussed by the teachers, but instead beginning teachers have to depend on guesswork as they negotiate their way through school life (Kelchtermans and Ballet 2002; Author 2 et al. 2015). This issue is accentuated in the wider Japanese cultural context, in which indirect communication and the maintenance of social harmony are greatly valued (Kondo 1990; Sugimoto 2003). These tensions are also connected to cultural expectations and general principles, which are often realised in concrete form in the school's practices. The expectations become visible when they are transgressed, such as in the "candy episode' (see Section 4.2). As well as being characteristic of Japanese (organisational) culture, the tensions in the senior teacher-beginning teacher relationships also relate to the specifics of the local 
context (e.g. the lack of midcareer teachers). As in our earlier research, the teachers' expectationsthat is, their ideals — often clashed with what was permitted in the school regarding teaching practices (Lassila and Uitto 2016).

In summary, this study shows that for beginning teachers, relational tensions relate strongly to their ability (or lack of ability) to manage the expectations and practical duties of being both an individual teacher and a member of the school's teacher community. These findings illustrate how beginning teachers need to carefully consider their position and actions towards their seniors, and this is further complicated by the contradictions between many of the expectations placed upon them. Then again, in the case of the senior teachers, tensions relate to when and how much to guide the beginning teachers and when to leave them on their own, as well as how best to teach the beginning teachers, knowing that while harsh lessons are educative, they may make some beginning teachers still more timid. Struggling with this tension can lead to senior teachers to send mixed messages to the beginning teachers, in turn increasing uncertainty for the beginning teachers as they struggle how to interpret and act upon these conflicting expectations.

Even though the relationships among teachers at K-school were quite warm and good (based on Erkki's observations and discussions), when explicitly mentioned in the interviews, they were often told as more complex and tension-filled.The experience of the tension itself was often connected to fear or insecurity.

\section{Implications}

Increased understanding of the tensions in the relationships between beginning and senior teachers as inherent to teaching and of the role these tensions play in the relational dimension of the teachers' work can help teachers to achieve greater control and influence over their working conditions and improve their well-being (see Lassila and Uitto 2016). Even if unsuccessful, the process of addressing these tensions can enhance teachers' professional development (Kelchtermans and Ballet 2002); therefore, future research should investigate in more detail how teacher education might best acknowledge these tensions and prepare teachers for this aspect of their work. In a 
similar fashion, Toompalu, Äli and Kullasepp (2016) suggest equipping student teachers with psychological coping skills to help them deal better with emotionally difficult situations and pedagogical dilemmas. One approach could be to invite teacher educators to unpack and problematise some of their own existing teaching practices in preservice teacher education, as the tensions that teacher educators experience when nurturing future teachers are very similar to the difficulties faced by senior teachers in deciding how best to guide beginning teachers (see Berry 2008).

In schools, rather than pretending that relational tensions do not exist or silencing them for social and political reasons, it would be beneficial for all stakeholders to create a culture where these issues could be more openly communicated and discussed. Introducing this kind of change in school culture and practices is clearly difficult, but beginning teachers - however capable and knowledgeable they may be about their school's micropolitical environment or associated tensions - are unlikely to achieve change unaided or alone, and therefore the participation of senior teachers, especially school leaders, in this process is crucial.

\section{Acknowledgements}

We are grateful to Professor Geert Kelchtermans, University of Leuven, Belgium, for providing feedback on the article in its different stages as a visiting professor at the University of Oulu.

\section{References}

Ahn, Ruth. 2014. How Japan supports novice teachers. Educational Leadership 71 (8): 49-53.

Andô, Tomoko. 2005. Kyôshi no kattô taisho yôshiki ni kansuru kenkŷ̂ [Research on patterns on how to deal with conflicts in teachers' work]. Tokyo: Taga shuppan.

Aultman, Lori Price, Meca R. Williams-Johnson and Paul A. Schutz. 2009. Boundary dilemmas in teacher-student relationships: Struggling with the "line". Teaching and Teacher Education 25 (5): 636-646. https://doi.org/10.1016/j.tate.2008.10.002 
Ávila de Lima, Jorge. 2001. Forgetting about friendship: Using conflict in teacher communities as catalyst for school change. Journal of Educational Change 2 (2): 97. https://doi.org/10.1023/A:1017509325276

Ballet, Katrijn and Geert Kelchtermans. 2009. Struggling with workload: Primary teachers' experience of intensification. Teaching and Teacher Education 25 (8): 1150-1157. DOI: 10.1016/j.tate.2009.02.012

Berry, Amanda. 2008. Tensions in teaching about teaching - Understanding practice as a teacher educator. Dordrecht: Springer.

Britzman, Deborah. 2003. Practice makes practice: A critical study of learning how to teach. Albany: State University of New York Press.

Caspersen, Joakim and Finn Daniel Raaen. 2014. Novice teachers and how they cope. Teachers and Teaching: Theory and Practice 20 (2): 189-211.

http://dx.doi.org/10.1080/13540602.2013.848570

Clandinin, Jean D. and Michael F. Connelly. 2000. Narrative inquiry: Experience and story in qualitative research. San Franciso: Jossey-Bass Publishers.

Clandinin, Jean D., M. Shaun Murphy, Janice Huber and Anne Murray Orr. 2009. Negotiating narrative inquiries: living in a tension-filled midst. The Journal of Educational Research 103 (2): 81-90. http://dx.doi.org/10.1080/00220670903323404

Devos, Christelle, Vincent Dupriez and Léopold Paquay. 2012. Does the social working environment predict beginning teachers' self-efficacy and feelings of depression? Teaching and Teacher Education 28 (2): 206-217. https://doi.org/10.1016/j.tate.2011.09.008

Elbaz-Luwisch, Freema. 2005. Teachers' voices: Storytelling and possibility. Greenwich, CT: Information Age Publishing. 
Flores, Maria A. 2004. The impact of school culture and leadership on new teachers' learning in the workplace. International Journal of Leadership in Education 7 (4): 297-318. http://dx.doi.org/10.1080/1360312042000226918

Gubrium, Jaber F. and James A. Holstein. 2008. Narrative ethnography. In The handbook of emergent methods, edited by Sharlene Nagy Hesse-Bieber and Patricia Leavy, 241-264. New York: Guilford Publications.

Harfitt, Gary James. 2015. From attrition to retention: A narrative inquiry of why beginning teachers leave and then rejoin the profession. Asia-Pacific Journal of Teacher Education 43 (1): 22-35. http://dx.doi.org/10.1080/1359866X.2014.932333

Hargreaves, Andy. 1998. The emotional practice of teaching. Teaching and Teacher Education 14 (8): $835-854$.

Hargreaves, Andy. 2000. Mixed Emotions: Teachers' perceptions of their interactions with students. Teaching and Teacher Education 16 (8): 811-826. https://doi.org/10.1016/S0742051X(00)00028-7

Hargreaves, Andy. 2001. The Emotional Geographies of Teachers' Relations with Colleagues. International Journal of Educational Research 35 (5): 503-527. https://doi.org/10.1016/S08830355(02)00006-X

Howe, Edward. 2005. Japan's teacher acculturation: Critical analysis through comparative ethnographic narrative. Journal of Education for Teaching: International Research and Pedagogy 31 (2): 121-131.

Josselson, Ruthellen. 2007. The ethical attitude in narrative research: Principles and practicalities. In Handbook of narrative inquiry: Mapping a methodology, edited by Jean D. Clandinin, 537566. London: Sage Publications. 
Kelchtermans, Geert. 1994. Biographical methods in the study of teachers' professional development. In Teacher thinking and action in varied contexts. Research on teachers ' thinking and practice, edited by Ingrid Carlgren, Gunnar Handal and Sveinung Vaage, 93-106. London, Falmer Press.

Kelchtermans, Geert. 2005. Teachers' emotions in educational reforms: Self-Understanding, vulnerable commitment and micropolitical literacy. Teaching and Teacher Education 21 (8): 995-1006. https://doi.org/10.1016/j.tate.2005.06.009

Kelchtermans, Geert and Katrijn Ballet. 2002. The micropolitics of teacher induction: A narrativebiographical study on teacher socialisation. Teaching and Teacher Education 18 (1): 105-120. https://doi.org/10.1016/S0742-051X(01)00053-1

Kondo, Dorinne. 1990. Crafting selves. Chicago: University of Chicago Press.

Kuzmic, Jeff. 1994. A beginning teacher' s search for meaning: Teacher socialization, organizational literacy, and empowerment. Teaching and Teacher Education 10 (1): 15-27. https://doi.org/10.1016/0742-051X(94)90037-X

Lassila, Erkki T. 2017. Tensions in the relationships - Exploring beginning Japanese teachers' stories. Doctoral thesis. Oulu, University of Oulu. http://urn.fi/urn:isbn:9789526214764Lassila, Erkki and Minna Uitto. 2016. The tension between the ideal and experienced: Teacher-student relationships in stories told by beginning Japanese teachers. Pedagogy, Culture and Society 24 (2): 205-219. http://dx.doi.org/10.1080/14681366.2016.1149505

Le Maistre, Cathrine and Paré, Anthony. 2010. Whatever it takes: How beginning teachers learn to survive. Teaching and Teacher Education 26 (3): 559-564.

Lieblich, Amia, Rivka Tuval-Mashiach and Tammar B. Zilber. 1998. Narrative research: Reading, analysis and interpretation. Thousand Oaks: Sage. 
Meijer, Debra K. 2011. Entering the emotional practices of teaching. In Advances in teacher emotion research - the impact on teachers' lives, edited by Paul A, Schutz and Michaelinos Zembylas, 7391. New York: Springer.

Miyajima, Tomomi. 2008. Gender inequality among Japanese high school teachers: Women teachers' resistance to gender Bias in occupational culture. Journal of Education for Teaching 34 (4): 319-332.

Moje, Elisabeth. 2000. Changing our minds, changing our bodies: Power as embodied in research relations. International Journal of Qualitative Studies in Education 13 (1): 25-42. http://dx.doi.org/10.1080/095183900235717

Newberry, Melissa. 2010. Identified phases in the building and maintaining of positive teacherstudent relationships. Teaching and Teacher Education 26 (8): 1695-1703. https://doi.org/10.1016/j.tate.2010.06.022

Nussbaum, Martha. 2001. Upheavals of thought: The intelligence of emotions. Cambridge: Cambridge University Press

Okano, Kaori and Motonori Tsuchiya. 1999. Education in contemporary Japan: Inequality and diversity. Cambridge: Cambridge University Press.

Peters, Judith and Jane Pearce. 2012. Relationships and early career resilience: a role for school principals. Teachers and Teaching: Theory and Practice (2): 249-262. http://dx.doi.org/10.1080/13540602.2012.632266

Pillen, Marieke, Douwe Beijaard and Perry den Brok. 2013. Professional identity tensions of beginning teachers. Teachers and Teaching: Theory and Practice 19 (6): 660-678. http://dx.doi.org/10.1080/13540602.2013.827455 
Raz, Aviad E. 2002. Emotions at work: Normative work: Normative control, organizations, and culture in Japan and America. London: The Harvard University Asia Center.

Rohlen,Thomas P. 1991. Up and down. In Transcending stereotypes - Discovering Japanese culture and education, edited by Barbara Finkelstein, Anne E. Imamura and Joseph Jay Tobin, 20-25. Yarmouth: Intercultural Press.

Shapira-Lishchinsky, Orly. 2011. Teachers' critical incidents: Ethical dilemmas in teaching practice. Teaching and Teacher Education 27 (3): 648-656. https://doi.org/10.1016/j.tate.2010.11.003

Shimahara, Nobuo K. 2002. Teaching in Japan: A Cultural Perspective. New York: Routledge Falmer.

Smeed, Judy L, Megan Kimber, Jan Millwater and Lisa Ehrich. 2009. Power over, with and through: Another look at micropolitics. Leading and Management 15 (1): 26-41.

Southgate, Erica. 2003. Remembering school. Mapping continuities in power, subjectivity, and emotion in stories of school life. New York: Peter Lang.

Sugimoto, Yoshio. 2003. An introduction to Japanese society. New York: Cambridge University Press.

Toompalu, Aivi, Äli Leijen and Katrin Kullasepp. 2016. Professional role expectations and related feelings when solving pedagogical dilemmas: A comparison of pre- and in-service teachers. Teacher Development 21(2): 307-323. DOI: 10.1080/13664530.2016.1237985

Uitto, Minna, Saara-Leena Kaunisto, Leena Syrjälä and Eila Estola. 2015. Silenced truths: Relational and emotional dimensions of a beginning teacher's identity as part of the micropolitical context of school. Scandinavian Journal of Educational Research 59 (2): 1-15. http://dx.doi.org/10.1080/00313831.2014.904414 
Veenman, Simon. 1984. Perceived problems of beginning teachers. Review of Educational Research 54 (2): 143-178.

Wakimoto, Takehiro and Daisuke Chôshi. 2015. Kyôshi no manabi wo kagaku suru deeta kara mieru wakate no ikusei to jukutatsu no moderu. [Professional development model for young teachers based on data on teachers' learning] Kyoto: Hokudairoshodô.

Zeichner, Kenneth M. and Jennifer M. Gore. 1990. Teacher socialization. In Handbook of research on teacher education, edited by Robert W. Houston, 329-348. New York: MacMillan.

Zembylas, Michaelinos. 2004. The emotional characteristics of teaching: An ethnographic study of one teacher. Teaching and Teacher Education 20 (2): 185-201.

https://doi.org/10.1016/j.tate.2003.09.008

Zilber, Tammar B., Rivka Tuval-Mashiach and Amia Lieblich. 2008. The embedded narrative: Navigating through multiple contexts. Qualitative Inquiry 14(6): 1047-1069. DOI: $10.1177 / 1077800408321616$

\footnotetext{
${ }^{\mathrm{i}}$ Erkki,originally from Finland, has studied the language since 2005 and has passed the highest level of Japanese language proficiency test. He has lived in Japan during 2007 - 2008 and 2013-2016. During the latter period he conducted the empirical part of this research. The co-authors, Minna and Eila (situated in Finland) became involved in the analysis and writing stage of the research.
}

ii Organised at least once a year by the prefectural boards of education and separately for different school levels and subjects.

iii Many schools in Japan struggle with this demographic anomaly (Wakimoto and Chôshi, 2015).

iv It is typical in Japanese culture for different social groups to gather around for eating and drinking. 